\title{
Digitising a Learning Activity: Challenges and Opportunities
}

\section{Jowati Juhary}

Language Centre, National Defence University of Malaysia, Malaysia.

\begin{abstract}
As the world faces the new landcape in teaching and learning due to COVID19, the pandemic, the strategies and approaches use for teaching and learning must ensure all students have access to digital resources. This paper explores the challenges and opportunities faced by the researcher and her students when a learning activity previously implemented in face-to-face sessions was transferred into an online learning environment. The learning activity, known as Work-the-Walk (WTW), is a transformative learning activity designed by the researcher, and the researcher owns the copyright of WTW. The objectives of this paper are to identify the challenges and opportunities raised by transferring WTW to a digital format, and ultimately to suggest the best ways to make the transition from a physical learning activity to a digital format effectively. Qualitative approach to research was used to obtain data for analysis and discussion. Preliminary findings suggest that the Digital WTW (D-WTW) present two main challenges and two main opportunities for both the researcher and students. Given this, the education providers must be willing to encourage the educators to provide various approaches to teaching and learning, as well as to promote experiments with various existing learning strategies used in face-to-face sessions, and to transfer them to be used in an online learning environment.
\end{abstract}

Keywords: D-WTW; learning activity; online learning environment; teaching and learning; WTW. 


\section{Introduction}

The past one year has seen massive changes in the ways students learn, and the ways educators teach. Affected by COVID-19, education has been reported to be one of the distrupted sectors in the world (Demirbas, Bozkurt, \& Yorgun, 2020). Despite the lack of physical schooling in 2020, educators struggle to complete the syllabi, and students struggle to learn fully online and score in assessments. From physical classes to blended learning, and now to fully online learning, education must continue to ensure all students get access to relevant resources to improve their life and those dependent upon them in the future.

This paper attempts to explore the challenges and opportunities in using a learning activity designed for face-to-face sessions in an online learning environment. The learning activity, known as Work-the-Walk (WTW), was designed by the researcher, and has been used in her face-to-face sessions for eight semesters, prior to the application for copyright of WTW. With the pandemic cancelling physical class and the associated class activities, the researcher has applied WTW online using existing platforms that are available. Therefore, data for this paper were collected at the National Defence University of Malaysia (NDUM), where the researcher teaches, and the users for her Digital WTW (D-WTW) were her students.

Given the paradigm shift in the process of teaching and learning, all education providers, including the NDUM must prepare a suitable online teaching and learning environment. This can start with the teaching and learning activities that could be adapted and transferred into an online learning environment. As mentioned earlier, the aim of this paper is to explore the challenges and opportunities to use a learning activity designed for face-to-face sessions in an online learning environmnet. Thus, there are two main objectives of this paper including, to identify the challenges and opportunities raised by transferring WTW to a digital format, and to recommend the best ways to adapt and transfer physical learning activities to an online format.

This paper has two main research questions that will achieve the aim and objectives of the study. These research questions include,

a. What are the challenges and opportunities when transferring WTW to a digital format?

b. How best to transfer the existing learning approaches used in face-to-face sessions into an online learning environment?

\section{An Overview of WTW}

This section explains the learning activity for face-to-face sessions, WTW, including the philosophy and practices (implementation). Since WTW was designed by the researcher about four years ago, and has been used in her physical classes, there are no formal 
documentations and citations about the activity available. Thus, this section concentrates on its philosophy, designs and development, types of WTW, and how WTW is implemented.

Taking advantages of the flipped classroom strategy (see McCarthy, 2016), the researcher has stopped conducting lectures about four years ago. Instead, she uses the face-to-face sessions to conduct engaging activities to complement the notes uploaded in the Learning Management System of the NDUM. These activities arguably have been a form of transformative learning, which is active and collaborative. Students are required to understand the learning materials uploaded, which include videos, reading materials and pictures or diagrams, before attending the face-to-face sessions. The classes start with questions to probe students' understanding of the previous lessons, and to connect to the lessons of the day. Socratic dialogues, a method of questioning and probing for appropriate answers, are used to sharpen students' perspectives on previous, and lessons they are about to explore. WTW begins when students have no more questions.

WTW requires activities to be conducted in smaller groups. In these groups, students must brainstorm, and discuss the lessons (the critical concepts) of the day. Then, they will go to the white board, which is placed around the classroom (this arrangement of the classroom is inspired by the classrooms at the United States Military Academy, West Point). At the white board, they mind map the important concepts (see Picture 2 for an example of the mind mapping on a white board). These brainstorming and mind mapping encourage active, collaborative, exploratory learning and increase problem solving and communication skills.

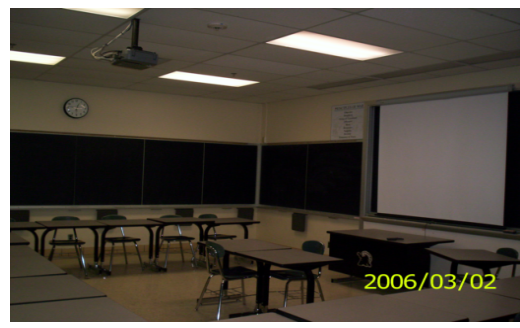

Figure 1. The Classroom at West Point (The Researcher, 2006)

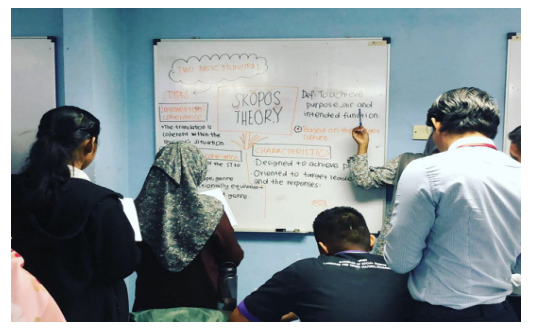

Figure 2. WTW (Concurrent) (The Researcher, 2018)

Over the period of four years, WTW has been expanded into four types of implementations. Each type is able to stand on its own or they can be used in a combination of any two. The types of WTW include (where mind mapping is already on the board),

a. WTW (Free Flow) - One student from each small group presents the critical concepts to the rest of the class. The presentation is conducted at the white board, where all students will gather. The researcher offers feedback on what has been explained and asks questions or adds, when appropriate. Students are encouraged to ask questions. 
b. WTW (Rotation) - All small groups move from one white board to the other, which surround the class. All groups are able to read the critical concepts mapped by the other groups. They are also encouraged to add any missing information on other groups' mind map. About five to seven minutes are spent per white board before they rotate to other boards. The researcher visits randomly any board and listens to the discussions, adding where necessary, and correcting when needed.

c. WTW (Concurrent) - A representative from each group visits white boards of other groups; at a time concurrently, if there are five groups, that suggests that four group members will be visiting the other four groups' boards. Then the host of the white boards explains to the 'visitors' the critical concepts of his/her group. After question and answer sessions, 'visiting' members return to their groups and explain what they learn from the other four boards. The researcher allows for a 10-minute discussion before inviting representatives from each group to explain other groups' critical concepts. Missing or incorrect information is added on the relevant white boards.

d. WTW (Visual) - Students in smaller groups are to draw pictures or sketches to demonstrate their critical concepts. No texts are allowed on the board. Similar to WTW (Rotation), students will shift from one white board to the other, and discuss the visual. The researcher then asks questions when the groups have returned to their own white boards. Changes to the visuals will be done based on the discussions.

The rationales of using WTW are twofold. First, in order to prepare the future graduates to face Industrial Revolution 4.0, they need to be effective critical thinkers and problem solvers (Gray, 2016). It is argued that WTW could train students to be effective future leaders. Second, the Ministry of Higher Education, Malaysia encourages all education providers to expose students to be more active and collaborative, and thus, students must be developed using heutagogy (self-determined learning) and paragogy (peer-oriented learning). Further, learning, according to Higher Education 4.0 (Amanat Menteri Pendidikan, 2018), should be without lectures.

\section{Methodology}

This paper adopts a qualitative approach to research by means of observations and informal WhatsApp interviews. Since the researcher only adopts D-WTW for the past two semesters during the emergency remote teaching phase, D-WTW can be considered at its infancy. There are two critical stages; first students must be made aware of WTW as a learning activity from the face-to-face sessions, and then they would be informed of the similarity to D-WTW. DWTW was used for eight hours in both courses taught by the researcher. During the execution of D-WTW, students were observed online on how they collaborated, and how they presented ideas. Second, selected students were interviewed informally about D-WTW. Four questions 
(see questions in Section 4.2) were asked. These questions were posted in the main WhatsApp groups of the two courses, and students were invited to answer them voluntarily.

At the time of writing this paper, only the first WTW (Free Flow) was transferred to a digital format. The implementation of D-WTW (Free Flow) involves the use of Microsoft Teams (Ms Teams), a platform for video conferencing and Padlet, an online board, where both educators and students can collaborate, reflect, and share videos, pictures and/or links. Before the start of the lesson, the researcher prepared the link to the class on Ms Teams, and then prepared the board on Padlet; links to these were then shared with the students.

\subsection{Sample Population}

The researcher taught two different courses during Semester 1, Academic Session 2020/2021, which started in October 2020 and ended in the middle of February 2021. The number of students in these two courses were 80 . About 85 percent of the students were at home, and the other 15 percent was on campus, including military cadets and students, who did not have stable and access to the Internet at home. For the informal interviews conducted through WhatsApp, students were selected based on convenience; questions were asked on WhatsApp groups for each course, and all answers were documented based on themes.

\subsection{Research Instruments}

Two research instruments were used. For the observation strategy, a checklist was used to document students' online collaboration and presentation. The checklist consists of three items each for collaboration and presentation. Moreover, the scale for the checklist includes Yes, No and Not Observed. For the informal interviews, four questions asked were about the respondents' experience and preference for online learning activities, including D-WTW.

\section{Findings and Discussions}

The findings of this paper came from the observations and informal interviews conducted on WhatsApp. For the observations, six items were documented using the scale explained earlier. Meanwhile, four questions were asked during the informal interviews. Thus, this section begins with discussions on the observation checklist, followed by the themes found during the informal interviews on the process and challenges of D-WTW (Free Flow).

\subsection{Data from the Observation Checklist}

Based on Table 1, it could be deduced that students using D-WTW were able to collaborate and present during online activities. However, during the first attempt for both courses, students were not able to collaborate effectively online (such as slow response rate and questions were asked personally through Direct Message to the researcher). For the final year 
students, despite being exposed to WTW during their first year, the first attempt of D-WTW was a challenge for them too. For the other course, attended by first year students, the challenge is different since they had never had the exposure on WTW. Therefore, a briefing on how to participate in the learning activity was given, and questions were entertained on roles of each member during D-WTW.

What can be discerned further is that backchanneling must have happened. Backchanneling is argued to be a technique to monitor students' engagement and performance in learning (Reinders, 2014). The researcher defines backchanneling as discussions that happen during an online lesson on WhatsApp; not in the main WhatsApp group in which the researcher was added as a member, rather another WhatsApp group amongst the students only. In order to complete the tasks assigned to them, the researcher argues that backchanneling did happen, otherwise students were not able to brainstorm, discuss and later present critical concepts (all these processes were not evident in the main WhatsApp group).

Table 1. The Observation Checklist for Collaboration and Presentation Online.

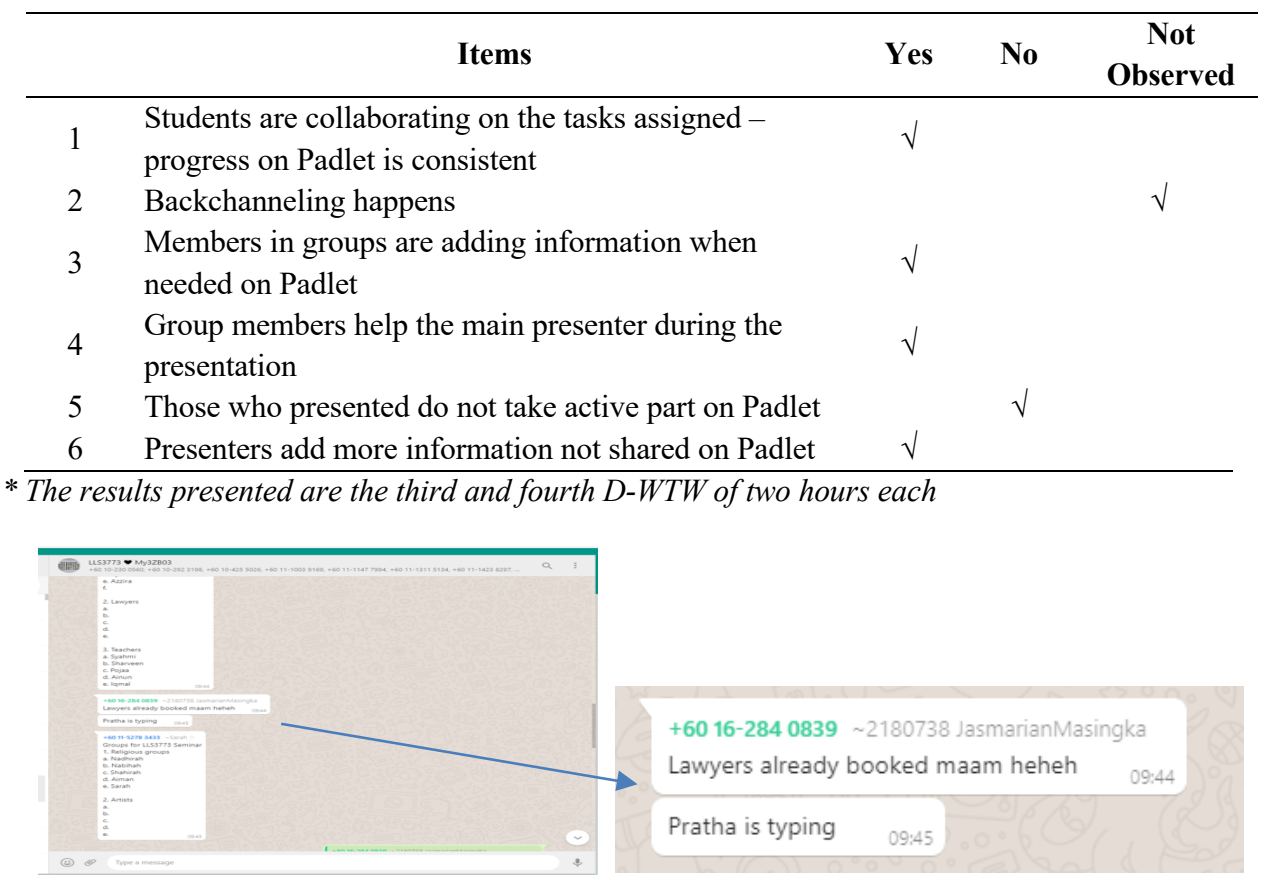

Fig 3. The Screenshot on a proof of Backchanneling (from the main WhatsApp group of one course).

Whilst the researcher is unable to get the screenshot of the backchanneling activities on students' WhatsApp group, Figure 3 illustrates that backchanneling did happen when the students were required to discuss something amongst the students only. This screenshot is from the main WhatsApp group when the students were assigned to group themselves 
according to specific roles. Next, to further illustrate on the use of Ms Teams and Padlet for D-WTW, Figure 4 is an example of how D-WTW (Free Flow) is implemented online.

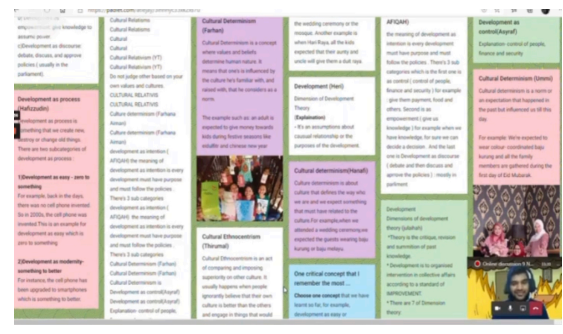

Fig 4. One example of D-WTW (Free Flow) on Ms Teams and Padlet.

\subsection{Data from Informal Interviews}

There were four questions asked during the WhatsApp interviews. The questions included, (a) Do you find it difficult to participate in this learning activity?; (b) What are the challenges of this learning activity?; (c) What are the things that can be improved for this learning activity?; and (d) What else do you think could help in this learning activity? The learning activity refers to D-WTW (Free Flow), as well as the use of Ms Teams, where everyone is able to monitor the activity, and the use of Padlet to collaborate and later to present ideas.

Based on these questions, three main themes emerge, including access and stability to the Internet, working collaboratively, and becoming more confident. These are further explained in Table 2 below. It is deduced that D-WTW (Free Flow) has improved students' collaboration with peers, and their confidence in presentation. Whilst it is hard to explain this scenario, the researcher opines that the students are Digital Natives, and that they adapt better to an online learning environment.

Table 2. Themes emerge from the Informal Interviews.

\begin{tabular}{clcc}
\hline \multicolumn{1}{c}{ Themes } & $\begin{array}{c}\text { First Year } \\
\text { (Course LLS3324) }\end{array}$ & $\begin{array}{c}\text { Final Year } \\
\text { (Course LLS3773) }\end{array}$ \\
\hline 1 & Internet stability and connection & 3 & 5 \\
2 & Improve Collaboration & 2 & 4 \\
3 & Improve Confidence & 3 & 4 \\
\hline
\end{tabular}

Because answering the questions was on voluntary basis, only eight respondents from both courses responded (see Table 2). Further examination on the table suggests that these eight respondents commented that they had issues with Internet connection as well as its stability. Given this, they further commented that they found all learning activities online became difficult, and they were disrupted by it. Nonetheless, six respondents claimed that they found D-WTW improves their teamwork with their peers when they were able to collaborate effectively. One first year respondent said that it was a challenge to work with 'unknown' 
friends because they had never met 'face-to-face' and worked together before. However, after a few weeks, they were able to build the bond and collaborate better. Seven respondents further claimed that their confidence level has increased when they had to do presentation.

\section{Conclusion}

There are two main research findings of this paper; challenges and opportunities of digitising learning activities designed for face-to-face sessions. Challenges of digitising physical learning activities are; firstly, students found that without Internet connection and stability, it becomes difficult for them to participate in D-WTW (Free Flow), and secondly, students with zero experience with WTW required more time to understand how to be engaged in DWTW. Moreover, there are also two opportunities of digitising physical activities. Firstly, students, who are used to physical activities can easily adapt whatever that they had experienced in face-to-face sessions into an online learning environment. Secondly, the educators are able to use whatever appropriate physical learning activities, and then digitise them to be implemented online accordingly.

In addition, educators may digitise their physical learning activities in two ways. Firstly, educators must not be afraid to experiment - 'trial and error.' They can use any existing learning activities, and digitise them using online platforms and apps available. Secondly, choose learning activities that educators are familiar and comfortable with, and choose easy to handle online platforms or apps such as Padlet.

To conclude, much is still needed to be done in order to ensure that D-WTW could benefit students to the fullest. At its infancy, only WTW (Free Flow) is effectively digitised - DWTW (Free Flow). The other types of WTW may require different platforms and apps other than Padlet to make them achieve their potential of assisting students to learn. The researcher opines that with more experiments on digitising learning activities, an online learning environment could match the face-to-face session experience.

\section{References}

Amanat Menteri Pendidikan. (2018). Putrajaya: Ministry of Higher Education Malaysia.

Demirbas, D., Bozkurt, V. \& Yorgun, S. (2020). The COVID-19 Pandemic and Its Economic, Social, and Political Impacts. Istanbul: Istanbul University Press.

Gray, A. (2016). The 10 skills you need to thrive in the Fourth Industrial Revolution. World Economic Forum. Accessed 14 December 2020 at https://www.weforum.org/agenda/2016/01/the-10-skills-you-need-to-thrive-in-thefourth-industrial-revolution/.

McCarthy, J. (2016). Reflections on a Flipped Classroom in First Year Higher Education. Issues in Educational Research, 26(2), 332-350. 
Reinders, H. (2014). Backchanneling in the Language Classroom: Improving Student Attention and Retention with Feedback Technologies. The Journal of Language Teaching and Learning, 4(2), 84-91. 